\title{
An Emotion Recognition Based on Physiological Signals
}

\author{
Arvind Kumar, Nidhi Garg, Gurpreet Kaur
}

\begin{abstract}
Emotion recognition is alluring considerable interest among the researchers. Emotions are discovered by facial, speech, gesture, posture and physiological signals. Physiological signals are a plausible mechanism to recognize emotion using human-computer interaction. The objective of this paper is to put forth the recognition of emotions using physiological signals. Various emotion elicitation protocols, feature extraction techniques, classification methods that aim at recognizing emotions from physiological signals are discussed here. Wrist Pulse Signal is also discussed to fill the lacunae of the other physiological signal for emotion detection. Working on basic as well as non-basic human emotion and human-computer interface will make the system robust.
\end{abstract}

Keywords: Ayurveda, Emotion recognition system, Emotion elicitation protocols, Physiological signals, Wrist Pulse Signal

\section{INTRODUCTION}

Emotions are complex psychological processes that affect the facets of our lives. The human body and emotions are inseparable and affect each other [1]. Emotion recognition is a stimulating domain in the interaction of humans and machines [2,3]. Machines should be able to discern human emotions and to interact with humans in a natural way. Emotions supersede, emerge and wane according to a set of laws [4]. Emotions are productive in designing tutoring and developing robots [5-7]. Emotions are worthwhile in making a decision, learning capability and diverse functions [6]. Consequently, there is a need to create an emotion recognition system that is able to achieve high classification accuracy and adaptable to any artifacts [8].

Emotions are discovered by facial, speech, gesture, posture, physiological signals, etc [9]. The emotional method, for instance, facial and speech $[10,11]$ lack accuracy and rely on culture, age, and gender. By using these methods, emotions can be masked or suppressed. This lay the foundation for the physiological signals [12-16]. Human emotional experiences are dominated by two systems of human brain -

Central Nervous System (CNS) and the Peripheral Nervous System (PNS). PNS comprises - Autonomous Nervous System (ANS) and Somatic Nervous System (SNS) $[8,17]$. Physiological signals or Biosignals are governed by ANS The ANS system has outside voluntary control.

Revised Manuscript Received on July 22, 2019. Arvind Kumar, Nidhi Garg, Gurpreet Kaur, Panjab University, Chandigarh.
Therefore, Masking is not possible in physiological signals. Physiological signals are manifold in nature and attracted less attention than facial and speech signals. Physiological signals or biosignals which also encompasses Electrocardiogram (ECG) [18], Electromyogram(EMG)[13], Electroencephalogram(EEG)[19], Photoplethysmography (PPG) [20] , Skin Conductance (SC) [3] are used to assess the emotional states of humans. ECG is related to the cardiovascular system which measures the activity of heart, EMG relates the electrical activity of muscles, a Wrist pulse signal is not only related to heart but also to nerves, muscles, skin, etc[13,14,21]. Any changes in body condition are reflected in the human wrist pulse signal.

The emotion recognition system depends on the subject independent [12] and subject dependent [22] system. The subject dependent approach is not acceptable universally so it has been generally challenged by the researchers. It cannot be considered a standard for any research. Recently, researchers in the field of emotion recognition are eyeing a Subject independent approach i.e. representation in which classification is done on multiple and distinct subjects. But subject independent approaches put up a poor show as compared to subject dependent. Researchers have to make a compromise between these two approaches according to the application

Defining Emotions is grueling tasks in distinct areas over a prolonged duration of time. There are manifold theories of defining emotions. Researchers in the field of emotion recognition pay attention to two types of emotion models the discrete model and a dimensional model. These models have been used as a standard where emotions have their roots. The discrete model encompasses six basic emotions like happy, sad, fear, surprise, disgust, anger. Dimensional model represents emotions on two scales - valence and arousal. Valence scale symbolizes the polarity of emotion and ranges from positive to negative [23]. Arousal symbolizes the intensity of emotion and it varies from low to high [18]. Figure 2 shows the six basic emotions mapped on a two-dimensional valence- arousal plane.

There exists another category of signals i.e. Wrist Pulse Signal (WPS) [24-27] or Nadi Parikshan among the physiological signals. WPS has its roots in Ayurveda and is used by Indian physicians since the Twelfth century. It was acquired from wrist position non- invasively in a subjective manner using three fingers index, middle, ring finger (Vat, Pitt, Kaph or Cun, Guan, Chi). Consequently, it was transformed into a computerized approach with the development of sensor technology. But it is still not popular among the researchers.WPS 
influenced by the flow of blood in the human body. It also gives an indication of the heartbeat and distinct organs of the human body. Pulse signals are not a deterministic signal i.e. it cannot be represented by mathematical relations. The emotion recognition system can also be explored using this signal. WPS is similar to ECG. Moreover, ECG is used for emotion recognition which gives information about the working of the heart. Similarly, WPS could be used for a similar task of emotion recognition [28-30].WPS also has edge over ECG as it unravels the additional information about organs. The distinct set of emotions can be invoked within the subject using emotion elicitation protocols and pulse signals are acquired from the radial artery.

This paper gives an insight into various emotion elicitation protocols, feature extraction techniques, classification methods that aim at recognizing emotions from physiological signals. The focus of this paper is to fill the lacunae in earlier researches like subject dependent, classification accuracy and propound a best possible solution. Distinct sections are given as follows: Section II Material and Methods narrates emotion elicitation protocols used, data acquisition, preprocessing, feature extraction, classification. Section III Comparison table highlights previous works done by researchers and their findings. Section IV Future work set forth the challenges and future trends, Section V Conclusion culminates with emotion recognition.

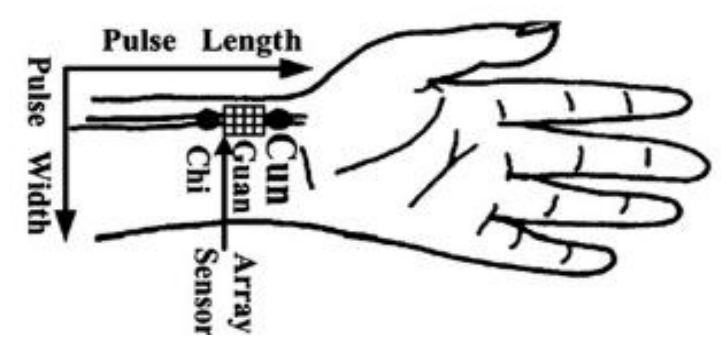

Fig. 1: Wrist pulse points[30]

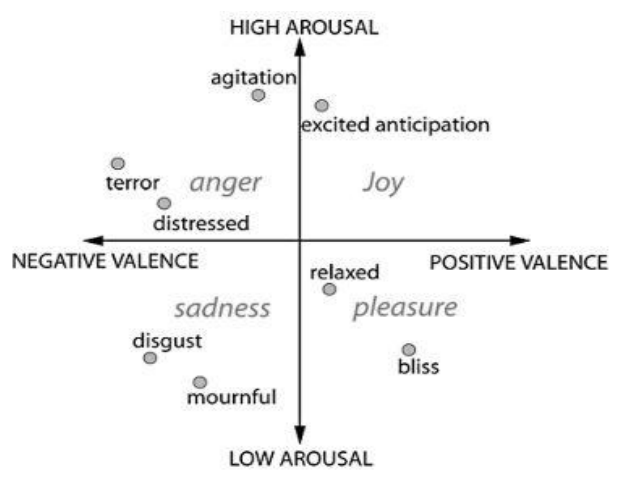

Fig. 2: Two- Dimension model of all emotions in AV plane[18]

\section{MATERIAL AND METHODS}

\section{A. Emotion Elicitation Protocols}

Physiological signals cannot be masked externally so there entails an emotion elicitation internally in the subject. The stimulus is pertinent for a notable response. There exists profuse emotion elicitation methods which encompass pictures of International Affective Picture System (IAPS)
[31,32], music[3], audio and audio video[12,13] etc. The intensity of emotions differs from subject to subject. These physiological signals can only be comprehended by the specialists. The clips are espoused according to the specific rating from participants. These protocols must be capable of eliciting target emotion among the subjects. Audiovisual is found to be better to evoke the emotions [13]. Emotion elicitation protocols were used in the prior study for evoking basic emotions as shown in figure 3 .These protocols in prior studies manifest that emotion elicitation nearly requires half to one hour. This can be divided into two sessions. The selected video clips by rating are displayed for a specific time period Neutral emotions can be used in between the basic emotions. The two-dimensionally opposite emotions should not be used successively as specified in prior studies as it may not be helpful for the emotion elicitation within the subjects $[11,12,28]$. The clips should not be too long or too short. Before data acquisition, certain questions can be posed to the subject so as to emulate the data after the acquisition.

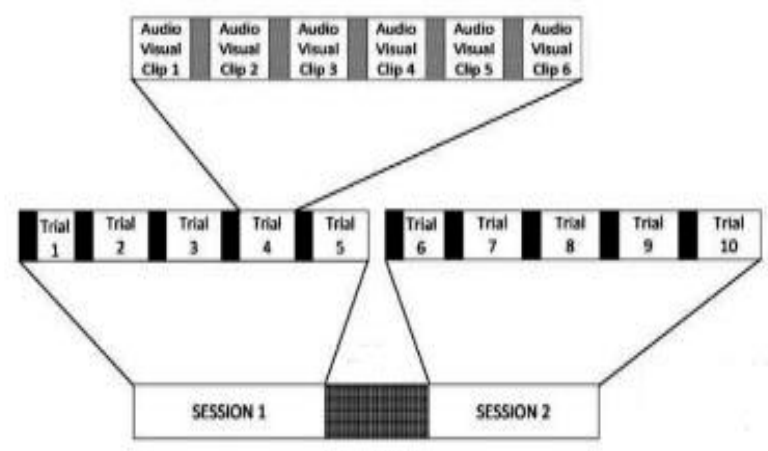

Fig. 3: Emotion Elicitation protocol [12]

\section{B. Data Acquisition}

Emotions are elicited using emotion elicitation protocol. These emotions are measured using a distinct number of data acquisition ways. The number of participants and their age, gender, etc is chosen according to the aim of work. The consent of the subjects is also pertinent and the goal of work is instructed to subjects [18]. The researchers should also take care that the subject should not be under undue pressure or stress. The experiment is performed in a quiet, isolated environment. Physiological signals are acquired at a required sampling frequency which depends on the type of physiological signals like ECG $(0.5-100 \mathrm{~Hz})$, EMG $(5-450 \mathrm{~Hz})$ and WPS $(0-30 \mathrm{~Hz})$. The hardware encompasses Electrodes [8,9], ProComp Infiniti system [13,24], BIOPAC MP150 [15,22], Kendal media Trace 500[19] etc were used in prior works. The data collected is fed to software for processing in Matlab, Labview [19,33]. Various databases have been established for efficient research works such as MIT, DEAP [34], DREAMER, and MAHNOB-HCI [35]

\section{Preprocessing}

Preprocessing is imperative in the examination of Physiological signals. The signal acquired by the hardware is affected by noise or outliers which degrade the 
signals $[36,37]$. The rationale behind these artifacts is the baseline wander (respiration), low-frequency noise (subject movement) wrongly placed electrode, high-frequency noise from devices, noise due to $50 \mathrm{~Hz}$ power line interference, white Gaussian noise. These outliers affect the signals and diminish accuracy. These artifacts should be removed to get accurate physiological signal analysis. Abating these degradations requires methods, for instance, sliding window [38], wavelet denoising [12,18,24,39,40], cascade filter [21], curve fitting [21], discrete Mayer model[36],Finite Impulse Response(FIR) filter. Even filters can be taken into service like notch filter [41], Butterworth [22], Chebyshev, Bandpass $[15,19,31]$.The sampling rate is even maintained much larger so that information will not be lost. Thus it becomes difficult for the researchers to analyze the behavior of physiological signals. Hence, the subject movement can also be controlled by the researcher so as to avoid the baseline wander.FIR Low pass filter can be designed in order to remove the high-frequency noise from power line interference.

Segmentation plays a pivotal role in the extraction of a single period from the absolute pulse signal. The signal obtained here is not of equivalent length due to a lot of variations. Consequently, Normalization is employed to equalize the physiological signals. The resulting signal is freed from the noise and ready for further processing.

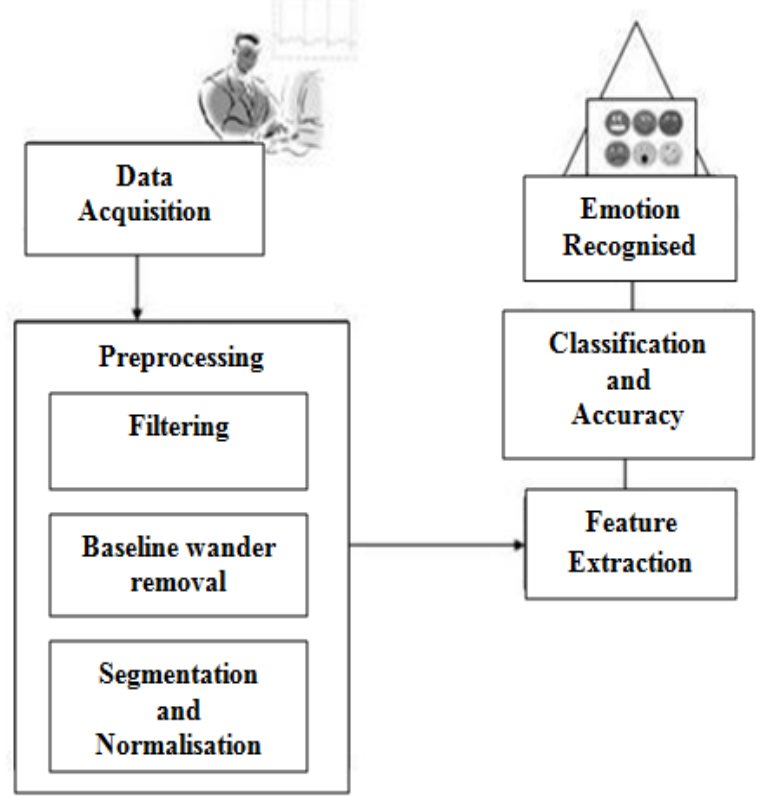

Fig. 4: Flowchart of the system

\section{Feature Extraction}

Once the signal is freed from unwanted outliers[5], succeeding development is feature extraction. Feature extraction is requisite for the further classification process so as to discern emotions. Researchers employ distinct domain to extract features from physiological signals, for instance, time domain, frequency, wavelet, neural network, etc. A total of 145 features were extracted from ECG and respiration by Cheng he et al [7]. Feature extraction methods encompass Empirical Mode Decomposition (EMD) [42-44] and Hilbert Huang Transform (HHT) [3,9,15], wavelet[45,46],Fourier transform $[47,48]$. Jerrita et al [12] employed an algorithm to integrate Empirical mode decomposition along with Hilbert transform and Fourier analysis extracted entropy and power of raw ECG signal. Haag et al [41] extract running mean, running standard deviation, Slope for ECG, BVP, Skin conductivity, EMG, Respiration, and Temperature using windowing techniques. These extracted features are processed to classification techniques.

\section{E. Classification}

Classification is an exemplar of supervised learning which is used to find the subcategories from the testing data. For instance, an animal is a super class and assigning given animals into the cat, dog, etc is classification. Classification implementation hinges on the data to be classified. Classifiers are problem dependent i.e. work well for particular problem vice versa. There are manifold classifiers available to classify emotional states using the feature extracted. These classifiers which encompasses Support vector machine (SVM) [3,14,15,31,32,46], K-Nearest Neighbour(KNN)[8,9,14,18, 49,50], Linear Discrminant Analysis(LDA)[8,11], Regression tree[3,9], Naiive Bayes[13], Fisher Linear Dicriminant [31], Artificial Neural Network(ANN)[2], RBF Neural Network $[41,45]$ etc .The comparison among these classifiers is done on the basis of accuracy.ECG Signal gives $52 \%$ accuracy $[12,13]$ but accuracy surges if more physiological are counted[15].

\section{PREVIOUS WORKS}

Various research works have been done in the field of emotion recognition, employing physiological signals. The focus of the researcher shifted from a single subject to multiple subjects. Different Stimuli for elicitation unravel distinct ways of emotion elicitation. Table I shows the related work on emotion recognition using physiological signals.

\section{Table I: Related works on emotion recognition using physiological signals}


An Emotion Recognition Based on Physiological Signals

\begin{tabular}{|c|c|c|c|c|c|c|c|}
\hline $\begin{array}{l}\text { Ref } \\
\text { No. }\end{array}$ & Biosignals used & $\begin{array}{c}\text { No. of } \\
\text { subjects }\end{array}$ & Emotions & Stimuli & $\begin{array}{c}\text { Technique and } \\
\text { Features }\end{array}$ & Classification & $\begin{array}{c}\text { Accuracy } \\
\%\end{array}$ \\
\hline \multirow[t]{2}{*}{ [3] } & \multirow{2}{*}{$\begin{array}{l}\text { Electrocardiogram, } \\
\text { Electromyogram, } \\
\text { Skin Conductivity, } \\
\text { Respiration changes }\end{array}$} & \multirow[t]{2}{*}{$\begin{array}{l}\text { MIT } \\
\text { database }\end{array}$} & \multirow[t]{2}{*}{$\begin{array}{l}\text { Joy,Pleasur } \\
\text { e,Anger, } \\
\text { Sadness }\end{array}$} & \multirow[t]{2}{*}{ Music } & \multirow[t]{2}{*}{$\begin{array}{l}\text { Hilbert Huang } \\
\text { Transform } \\
\text { (mean frequency) }\end{array}$} & \multirow[t]{2}{*}{$\begin{array}{l}\text { Support vector } \\
\text { Machine }\end{array}$} & 76(Fission) \\
\hline & & & & & & & 62 (Fusion) \\
\hline \multirow[t]{2}{*}{ [12] } & \multirow[t]{2}{*}{ Electrocardiogram } & \multirow[t]{2}{*}{30} & \multirow{2}{*}{$\begin{array}{l}\text { Basic } \\
\text { emotions } \\
\text { except } \\
\text { Anger }\end{array}$} & \multirow[t]{2}{*}{$\begin{array}{l}\text { Audio } \\
\text { visual }\end{array}$} & \multirow{2}{*}{$\begin{array}{l}\text { Hilbert Huang } \\
\text { Transform } \\
\text { Discrete Fourier } \\
\text { Transform } \\
\text { (Amplitude frequency } \\
\text { power } \\
\text { Entropy) }\end{array}$} & $\begin{array}{l}\text { K Nearest } \\
\text { Neighbour }\end{array}$ & 48.53(DFT) \\
\hline & & & & & & $\begin{array}{l}\text { Linear } \\
\text { discriminant } \\
\text { analysis }\end{array}$ & $52.11 \mathrm{DFT}$ \\
\hline \multirow[t]{2}{*}{ [13] } & \multirow[t]{2}{*}{ Electromyogram } & \multirow[t]{2}{*}{15} & \multirow{2}{*}{$\begin{array}{l}\text { Happy,Sad } \\
\text {,Afraid } \\
\text { Disgust } \\
\text { Neutral }\end{array}$} & \multirow[t]{2}{*}{$\begin{array}{l}\text { Audio } \\
\text { Visual }\end{array}$} & \multirow[t]{2}{*}{ Higher order statistics } & \multirow{2}{*}{$\begin{array}{l}\text { K Nearest } \\
\text { Neighbour } \\
\text { K Nearest } \\
\text { Neighbour, } \\
\text { Principal } \\
\text { component } \\
\text { analysis }\end{array}$} & 64.89 \\
\hline & & & & & & & 69.5 \\
\hline \multirow[t]{7}{*}{ [15] } & \multirow[t]{7}{*}{$\begin{array}{l}\text { Electrocardiogram, } \\
\text { Electrodermal } \\
\text { activity, Skin } \\
\text { temperature }\end{array}$} & \multirow[t]{7}{*}{217} & \multirow[t]{7}{*}{$\begin{array}{l}\text { Boredom, } \\
\text { Pain,Surpri } \\
\text { se }\end{array}$} & \multirow[t]{7}{*}{ Audio } & \multirow{7}{*}{$\begin{array}{l}\text { Heart rate ,Heart rate } \\
\text { variability,Ratio of } \\
\text { low to high frequency } \\
\text { power }\end{array}$} & $\begin{array}{l}\text { Discriminant } \\
\text { function } \\
\text { analysis }\end{array}$ & 84.7 \\
\hline & & & & & & $\begin{array}{l}\text { Linear } \\
\text { discriminant } \\
\text { analysis }\end{array}$ & 74.9 \\
\hline & & & & & & $\begin{array}{l}\text { Support vector } \\
\text { machine }\end{array}$ & 62 \\
\hline & & & & & & $\begin{array}{l}\text { Classification } \\
\text { and regression } \\
\text { tree }\end{array}$ & 67.8 \\
\hline & & & & & & Naiive Bayes & 71.9 \\
\hline & & & & & & $\begin{array}{l}\text { Self organizing } \\
\text { map }\end{array}$ & 61.5 \\
\hline & & & & & & $\begin{array}{l}\text { Self organizing } \\
\text { map }\end{array}$ & 61.5 \\
\hline \multirow[t]{2}{*}[31]{} & \multirow{2}{*}{$\begin{array}{l}\text { Blood Volume } \\
\text { pulse, } \\
\text { Electromyogram, } \\
\text { Electro dermal } \\
\text { activity } \\
\text { Skin Temperature } \\
\text { Respiration }\end{array}$} & \multirow{2}{*}{$\begin{array}{l}10 \text { (Inter } \\
\text { national } \\
\text { Affective } \\
\text { Picture } \\
\text { System) }\end{array}$} & \multirow{2}{*}{$\begin{array}{l}\text { Fear, } \\
\text { Disgust } \\
\text { Contentme } \\
\text { nt, Neutral } \\
\text { Sadness } \\
\text { Amuse }\end{array}$} & \multirow[t]{2}{*}{ Images } & \multirow[t]{2}{*}{$\begin{array}{l}\text { Statistical features } \\
\text { (Mean, Standard } \\
\text { deviation,etc) }\end{array}$} & $\begin{array}{l}\text { Support vector } \\
\text { Machine }\end{array}$ & $\begin{array}{l}\text { 45(subject } \\
\text { independent) }\end{array}$ \\
\hline & & & & & & $\begin{array}{l}\text { Fisher linear } \\
\text { discriminant } \\
\text { analysis }\end{array}$ & $\begin{array}{l}\text { 100(subject } \\
\text { dependent) }\end{array}$ \\
\hline
\end{tabular}




\begin{tabular}{|c|c|c|c|c|c|c|c|}
\hline \multirow[t]{2}{*}[18]{} & \multirow[t]{2}{*}{ Electrocardiogram } & \multirow[t]{2}{*}{60} & \multirow[t]{2}{*}{$\begin{array}{l}\text { Basic } \\
\text { Emotions } \\
\text { except } \\
\text { Anger }\end{array}$} & \multirow[t]{2}{*}{$\begin{array}{l}\text { Audio } \\
\text { Visual }\end{array}$} & \multirow{2}{*}{$\begin{array}{l}\text { Rescale Range } \\
\text { Statistics, } \\
\text { Finite Variance } \\
\text { Scaling, } \\
\text { Higher order } \\
\text { Statistics(Hurst,Skew } \\
\text { ness, Kurtiosis) }\end{array}$} & $\begin{array}{l}\text { Finite } \\
\text { Variance } \\
\text { scaling and } \\
\text { Higher order } \\
\text { statistics }\end{array}$ & $\begin{array}{l}92.87 \\
\text { (random) }\end{array}$ \\
\hline & & & & & & & $\begin{array}{l}76.45 \\
\text { (subject } \\
\text { independent) }\end{array}$ \\
\hline [32] & Electromyogram & $\begin{array}{l}\text { Inter } \\
\text { National } \\
\text { Affective } \\
\text { Picture } \\
\text { system }\end{array}$ & $\begin{array}{l}\text { Fear, } \\
\text { Disgust, } \\
\text { Sadness }\end{array}$ & Images & Wavelet Transform & $\begin{array}{l}\text { Support } \\
\text { Vector } \\
\text { Machine }\end{array}$ & $\begin{array}{l}81.82 \\
\text { (subject } \\
\text { Dependent) }\end{array}$ \\
\hline \multirow[t]{2}{*}{ [41] } & \multirow{2}{*}{$\begin{array}{l}\text { Electromyogram, } \\
\text { Electrocardiogram, } \\
\text { Electrodermal } \\
\text { activity, } \\
\text { Skin temperature } \\
\text { Blood Volume } \\
\text { pulse }\end{array}$} & \multirow[t]{2}{*}{ IAPS } & \multirow[t]{2}{*}{$\begin{array}{l}\text { Basic } \\
\text { emotions }\end{array}$} & \multirow[t]{2}{*}{ Images } & \multirow[t]{2}{*}{$\begin{array}{l}\text { Running mean, } \\
\text { Standard deviation, } \\
\text { Slope }\end{array}$} & \multirow{2}{*}{$\begin{array}{l}\text { Neural } \\
\text { Network } \\
\text { (Running } \\
\text { mean, } \\
\text { Standard } \\
\text { deviation, } \\
\text { Slope) }\end{array}$} & $\begin{array}{l}96.6 \\
\text { arousal }\end{array}$ \\
\hline & & & & & & & $\begin{array}{l}89.9 \\
\text { valence }\end{array}$ \\
\hline \multirow[t]{2}{*}{ [7] } & \multirow[t]{2}{*}{ Electrocardiogram } & \multirow[t]{2}{*}{$\begin{array}{l}\text { Augus- } \\
\text {-berg } \\
\text { database }\end{array}$} & \multirow[t]{2}{*}{$\begin{array}{l}\text { Joy, anger, } \\
\text { Sadness, } \\
\text { pleasure }\end{array}$} & \multirow[t]{2}{*}{ Music } & \multirow{2}{*}{$\begin{array}{l}\text { Db5 Multi scale } \\
\text { wavelet } \\
\text { Decomposition } \\
\text { (maximum and } \\
\text { standard deviation) }\end{array}$} & \multirow[t]{2}{*}{$\begin{array}{l}\text { Neural } \\
\text { Network }\end{array}$} & $91.67(\mathrm{RBF})$ \\
\hline & & & & & & & $87.5(\mathrm{BP})$ \\
\hline [51] & $\begin{array}{l}\text { Electrocardiogram } \\
\text { Electroencephalogr } \\
\text { am } \\
\text { Respiration }\end{array}$ & 6 & $\begin{array}{l}\text { Negative } \\
\text { Neutral }\end{array}$ & Videos & $\begin{array}{l}\text { Hilbert Huang } \\
\text { Transform }\end{array}$ & $\begin{array}{l}\text { Support } \\
\text { Vector } \\
\text { Machine }\end{array}$ & $\begin{array}{l}\text { 92.5(subject } \\
\text { dependent) }\end{array}$ \\
\hline
\end{tabular}

Though the prior studies take into account various methods and techniques there are certain lacunae that need to be addressed. The association of physiological signals with emotions becomes grueling task. Emotions rely on age, culture, time etc so physiological signals vary from person to person. Another problem is subject dependent and subject independent emotion recognition system. There is a dilemma in the mind of the researcher about these above systems. More emotions can also be classified apart from only basic emotions.

\section{FUTURE WORK}

In a current scenario, an emotion recognition system from the physiological signal is facing many challenges like subject independent approach gives less accuracy due to fewer data available. The number of emotions can also be added. Wrist pulse signals can also be explored using different ways. The number of subjects affects emotion recognition accuracy so more subjects to be included. The emotions which we encounter in our daily life cannot be elicitated up to the mark. Emotions recognition can contribute to the field of robotics. The genesis of proposed WPS was subjective but with the advancement in sensor technology it's shaped into objective field. WPS is an alluring field in the physiological signals using emotion recognition. The proposed WPS has more potential in the emotion recognition system as compared to other physiological signals.

\section{CONCLUSIONS}

This paper put forth the distinct phases of the emotions recognition system from physiological signals which provide analysis to the research. Recently, this field is in the nascent stage of its development due to the ample challenges it is facing today. The revolutionary approach is pertinent to have efficient feature extraction, classification techniques so as to get the subject independent system with maximum possible classification accuracy. Considerable data analysis is pertinent for emotion recognition. The researchers might contend to make the tradeoff between subject independent and subject dependent. Recently, developments in the wearable products will provide a platform for the emotion recognition system. The contemporary researches and its application will pave the way for more developments in the interaction of human and machine.

Published By: Blue Eyes Intelligence Engineering \& Sciences Publication 


\section{REFERENCES}

1. L. Bernardi et al., "Effects of controlled breathing, mental activity and mental stress with or without verbalization on heart rate variability," $J$. Am. Coll. Cardiol., vol. 35, no. 6, pp. 1462-1469, 2000.

2. H. Kim, K. Lee, and D. Kwon, "Emotional interaction model for a service robot," 2005 IEEE Int. Work. Robot. Hum. Interact. Commun., pp. 672-678, 2005.

3. C. Zong and M. Chetouani, "Hilbert-Huang transform based physiological signals analysis for emotion recognition," 2009 IEEE Int. Symp. Signal Process. Inf. Technol., pp. 334-339, 2009.

4. N. H. Frijda, "The Laws of Emotion," in American Psychologist, 1988, vol. 43, no. 5, pp. 349-358.

5. R. W. Picard, E. Vyzas, and J. Healey, "Toward machine emotional intelligence: analysis of affectivelnphysiological state," IEEE Trans. Pattern Anal. Mach. Intell., vol. 23, no. 10, pp. 1175-1191, 2001.

6. R. W. Picard, "Affective computing: Challenges," Int. J. Hum. Comput. Stud., vol. 59, no. 1-2, pp. 55-64, 2003.

7. C. He, Y. Yao, and X. Ye, "Wearable Sensors and Robots," vol. 399, 2017.

8. J. Kim and E. André, "Emotion recognition based on physiological changes in music listening," IEEE Trans. Pattern Anal. Mach. Intell., vol. 30, no. 12, pp. 2067-2083, 2008.

9. A. De and A. Saha, "A comparative study on different approaches of real time human emotion recognition based on facial expression detection," 2015 Int. Conf. Adv. Comput. Eng. Appl., pp. 483-487, 2015.

10. A. B. Ingale and D. S. Chaudhari, "Speech Emotion Recognition," no. 1, pp. 235-238, 2012.

11. O. E. Korkmaz and A. Atasoy, "Emotion Recognition from Speech Signal Using Mel-Frequency Cepstral Coefficients," pp. 1254-1257.

12. S. Jerritta, M. Murugappan, K. Wan, and S. Yaacob, "Electrocardiogram-based emotion recognition system using empirical mode decomposition and discrete Fourier transform," Expert Syst., vol. 31, no. 2, pp. 110-120, 2014.

13. S. Jerritta, M. Murugappan, K. Wan, and S. Yaacob, "Emotion recognition from facial EMG signals using higher order statistics and principal component analysis," J. Chinese Inst. Eng., vol. 37, no. 3, pp. 385-394, 2014.

14. Q. Li, Z. Yang, S. Liu, Z. Dai, and Y. Liu, "The Study of Emotion Recognition from Physiological Signals," Seventh Int. Conf. Adv. Comput. Intell., pp. 378-382, 2015.

15. E. H. Jang, B. J. Park, M. S. Park, S. H. Kim, and J. H. Sohn, "Analysis of physiological signals for recognition of boredom, pain, and surprise emotions," J. Physiol. Anthropol., vol. 34, no. 1, pp. 1-12, 2015.

16. H. Jerath and N. Garg, "Exploring Human Emotions Recognition Through Physiological Signals," vol. 10, no. 22, pp. 57-62, 2017.

17. Y. L. Hsu, J. S. Wang, W. C. Chiang, and C. H. Hung, "Automatic ECG-Based Emotion Recognition in Music Listening," IEEE Trans. Affect. Comput., pp. 1-16, 2017.

18. J. Selvaraj, M. Murugappan, K. Wan, and S. Yaacob, "Classification of emotional states from electrocardiogram signals: A non-linear approach based on hurst," Biomed. Eng. Online, vol. 12, no. 1, p. 1, 2013.

19. K. N. Minhad, S. H. M. Ali, and M. B. I. Reaz, "Happy-anger emotions classifications from electrocardiogram signal for automobile driving safety and awareness," J. Transp. Heal., vol. 7, no. November, pp. 75-89, 2017.

20. R. Ranjan, S. Conjeti, and R. Banerjee, "Biomedical Signal Processing and Control A comparative evaluation of neural network classifiers for stress level analysis of automotive drivers using physiological signals," Biomed. Signal Process. Control, vol. 8, no. 6, pp. 740-754, 2013.

21. D. Wang, D. Zhang, and G. Lu, "A robust signal preprocessing framework for wrist pulse analysis," Biomed. Signal Process. Control, vol. 23, pp. 62-75, 2016.

22. F. Agrafioti, D. Hatzinakos, and A. K. Anderson, "ECG pattern analysis for emotion detection," IEEE Trans. Affect. Comput., vol. 3, no. 1, pp. 102-115, 2012.

23 P. Ekman, R. W. Levenson, and W. V Friesen, "Autonomic nervous system activity distinguishes among emotions.," Science, vol. 221, no. 4616, pp. 1208-1210, 1983.

24. D. Rangaprakash and D. Narayana Dutt, "Study of wrist pulse signals using time domain spatial features," Comput. Electr. Eng., vol. 45, pp. 100-107, 2015.

25. K. Goyal and R. Agarwal, "Pulse based sensor design for wrist pulse signal analysis and health diagnosis .," vol. 28, no. 12, pp. 5187-5195, 2017.

26. M. S. Begum, “DIAGNOSING DISEASES THROUGH,” pp. 140-143, 2012.

27. R. Kaur, “Role of Pulse Diagnosis : A Review,”pp. 152-155, 2015.

28. B. Srinivasulu, "International Journal of Ayurveda and Pharma Research CLINICAL ASSESSMENT OF HYPOTHYROID SYMPTOMS IN DIFFERENT TYPES OF," vol. 1, no. 2, pp. 17-23, 2013.

29. P. J. Mills et al., "Journal of Ayurveda and Integrative Medicine Relationships among classi fi cations of ayurvedic medicine diagnostics for imbalances ( vikruti ) and western measures of psychological states : An exploratory study," J. Ayurveda Integr. Med., pp. 1-5, 2018.

30. Y. F. Chung, C. S. Hu, C. C. Yeh, and C. H. Luo, "How to standardize the pulse-taking method of traditional Chinese medicine pulse diagnosis," Comput. Biol. Med., vol. 43, no. 4, pp. 342-349, 2013.

31. C. Maaoui and a Pruski, "Emotion recognition through physiological signals for human-machine communication," Cut. Edge Robot., no. September 2010, pp. 317-333, 2010.

32. K. Gouizi, C. Maaoui, and F. Bereksi Reguig, "Negative emotion detection using EMG signal," Control. Decis. Inf. Technol. (CoDIT), 2014 Int. Conf., pp. 690-695, 2014.

33. A. Goshvarpour, A. Abbasi, and A. Goshvarpour, "Do men and women have different ECG responses to sad pictures?," Biomed. Signal Process. Control, vol. 38, pp. 67-73, 2017.

34. Y. Yaslan and C. E. Faculty, "Emotion Recognition via Random Forest and Galvanic Skin Response : Comparison of Time Based Feature Sets , Window Sizes and Wavelet Approaches," pp. 16-19, 2016.

35. S. Katsigiannis and N. Ramzan, "DREAMER: A Database for Emotion Recognition Through EEG and ECG Signals from Wireless Low-cost Off-the-Shelf Devices," IEEE J. Biomed. Heal. Informatics, vol. 22, no. 1, pp. 98-107, 2018.

36. B. Thakker and A. Vyas, "Outlier pulse detection and feature extraction for wrist pulse analysis," World Acad. Sci. Eng. Technol., vol. 3, no. 011 , pp. 173-176, 2009.

37. N. Garg, A. Bisht, H. S. Ryait, and A. Kumar, "Identification of motion outliers in wrist pulse signal," Comput. Electr. Eng., vol. 0, pp. 1-15, 2018.

38. Z. Zhang, Y. Zhang, L. Yao, H. Song, and A. Kos, “A sensor-based wrist pulse signal processing and lung cancer recognition," J. Biomed. Inform., vol. 79, no. May 2017, pp. 107-116, 2018.

39. W. Zuo, P. Wang, and D. Zhang, "Comparison of three different types of wrist pulse signals by their physical meanings and diagnosis performance," IEEE J. Biomed. Heal. Informatics, vol. 20, no. 1, pp. 119-127, 2016.

40. N. Garg, H. S. Ryait, A. Kumar, and A. Bisht, "An effective method to identify various factors for denoising wrist pulse signal using wavelet denoising algorithm," vol. 29, pp. 53-65, 2018.

41. A. Haag, S. Goronzy, P. Schaich, and J. Williams, "Emotion Recognition Using Bio-sensors: First Steps towards an Automatic System," pp. 36-48, 2004.

42. T. Chen, S. Ju, X. Yuan, M. Elhoseny, and F. Ren, "Emotion recognition using empirical mode decomposition and approximation entropy R," Comput. Electr. Eng., vol. 72, pp. 383-392, 2018.

43. N. Zhuang, Y. Zeng, L. Tong, C. Zhang, H. Zhang, and B. Yan, "Emotion Recognition from EEG Signals Using Multidimensional Information in EMD Domain," vol. 2017, 2017.

44. D.-Y. Zhang, W.-M. Zuo, D. Zhang, H.-Z. Zhang, and N.-M. Li, "Wrist blood flow signal-based computerized pulse diagnosis using spatial and spectrum features," J. Biomed. Sci. Eng., vol. 03, no. 04, pp. 361-366, 2010.

45. X. Guo,"Study of emotion recognition based on electrocardiogram and RBF neural network," Procedia Eng., vol. 15, pp. 2408-2412, 2011.

46. Y. Xu, G. Liu, M. Hao, W. Wen, and X. Huang, "Analysis of affective ECG signals toward emotion recognition," J. Electron., vol. 27, no. 1, pp. 8-14, 2010.

47. M. Jain and S. Saini, "A Hybrid Approach to Emotion Recognition System Using Multi-Discriminant Analysis \& K-Nearest Neighbour,' 2017, pp. 2251-2256.

48. I. Branch, P. Sciences, W. Island, S. Spring, N. Surface, and C. Division, "The empirical mode decomposition and the Hilbert spectrum for nonlinear and non-stationary time series analysis," 1998.

49. A. Albraikan, D. P. Tobon, and A. El Saddik, "Toward User-Independent Emotion Recognition using Physiological Signals," IEEE Sens. J., vol. PP, no. c, pp. 1-1, 2018.

50. G. K., "Pulse based sensor design for wrist pulse signal analysis and health diagnosis," Biomed. Res., vol. 28, no. 12, pp. 5187-5195, 2017.

51. X. Liu et al., "Human emotion classification based on multiple physiological signals by wearable system," Technol. Heal. Care, vol. 26, no. S1, pp. S459-S469, 2018. 


\section{AUTHORS PROFILE}

Dr. Nidhi is currently serving as Assistant Professor in ECE UIET, Panjab University, Chandigarh. Her research interests are biomedical signal processing, digital system design, embedded system. She has published paper in SCI and referred journals.

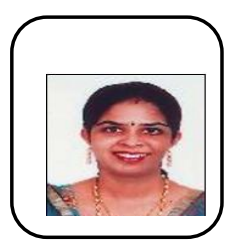

Dr.Gurpreet Kaur is currently serving as Assistant Professor in ECE UIET, Panjab University, Chandigarh.Her current research interests are speech processing and neural networks.

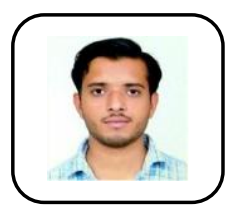

Arvind Kumar is pursuing ME ECE from Panjab University Chandigarh India. He completed his graduation from Guru Nanak Dev University Amritsar. His area of interest is biosignals processing and optical communication. 